\title{
Silencing the Peroxiredoxin III gene inhibits cell proliferation in breast cancer
}

\author{
PEI-JOU CHUA ${ }^{1}$, ENG-HONG LEE ${ }^{1}$, YINGNAN YU ${ }^{1}$, GEORGE WAI-CHEONG YIP ${ }^{1}$, \\ PUAY-HOON TAN ${ }^{1,2}$ and BOON-HUAT BAY ${ }^{1}$
}

\begin{abstract}
${ }^{1}$ Department of Anatomy, Yong Loo Lin School of Medicine, National University of Singapore, 4 Medical Drive, MD10, S 117 597; ²Department of Pathology, Singapore General Hospital, Outram Road, S 169608, Singapore
\end{abstract}

Received October 6, 2009; Accepted November 26, 2009

DOI: 10.3892/ijo_00000507

\begin{abstract}
Peroxiredoxin III (Prx III), an antioxidant protein found in mitochondria, plays an essential role in mitochondrial homeostasis. Aberrant expression of Prx III has been implicated in the tumorigenesis of various cancers. In this study, we evaluated the expression of Prx III in breast cancer tissues and elucidated its role in cell proliferation, a hallmark of cancer. Breast tissue microarrays comprising 106 breast cancer sections were stained with Prx III antibody using immunohistochemisty and correlated with proliferating cell nuclear antigen (PCNA) immunostaining. To validate the role of Prx III in cell proliferation, expression of Prx III was analyzed at the mRNA and protein levels by real-time RT-PCR, Western blotting and immunofluorescence in vitro. siRNA mediated silencing of Prx III in MDA-MB-231 breast cancer cells was performed and the effect on the cell cycle was examined. Prx III expression in patient tissue microarray samples was found to be positively associated with PCNA immunostaining, a proliferative marker. Prx III was expressed in both MCF-7 and MDA-MB-231 breast cancer cell lines and transient transfection with siPrx III in MDA-MB-231 cells induced inhibition of cell proliferation and cell cycle arrest. The data suggests that Prx III has a significant role in cell cycle regulation and could be a potential proliferation marker in breast cancer.
\end{abstract}

\section{Introduction}

The incidence of breast cancer worldwide has been ranked second after lung cancer (1). However, early detection and appropriate intervention has led to a decreasing rate of mortality in women afflicted with breast cancer. Due to the

Correspondence to: Dr B.H. Bay, Department of Anatomy, Yong Loo Lin School of Medicine, National University of Singapore, 4 Medical Drive, MD10, S 117 597, Singapore

E-mail: antbaybh@nus.edu.sg

Key words: Peroxiredoxin III, cell cycle, breast cancer, siRNA, cell proliferation heterogeneous molecular profiles in breast cancer, an understanding of breast cancer progression would improve the diagnosis and enhance the therapeutic outcome $(2,3)$.

Peroxiredoxins (Prxs) are highly conserved small proteins (22-27 kDa) that belong to a group of thiol-specific antioxidant enzymes which are able to catalyze the reduction of hydrogen peroxide $\left(\mathrm{H}_{2} \mathrm{O}_{2}\right)$ in the presence of thioredoxin (4-9). Prxs serve divergent functions such as protecting cells against oxidative stress, regulating cell signaling associated with $\mathrm{H}_{2} \mathrm{O}_{2}$ as a secondary messenger, and influencing cell differentiation and proliferation, immune response and apoptosis $(8,10,11)$. The six mammalian Prx isoforms identified can be further classified into three subgroups based on the content of redoxactive cysteine residues in the catalytic center which are involved in peroxidase activity (7).

Prx III, originally cloned out of murine erythroleukemia cells, is found exclusively in mitochondria due to the presence of a mitochondrial targeting sequence $(12,13)$. Prx III has been identified as a target gene induced by oncogenic c-Myc (14). Prx III was observed to be overexpressed in hepatocellular carcinoma (15) and breast carcinoma (16,17). Noh et al (16) observed no significant relationship between Prx III expression and clinicopathological parameters such as tumor size, lymphatic invasiveness, hormone receptor status and histological grade in 24 breast cancer tissues. However, increased expression of Prx III was found to be associated with hormonal receptor (estrogen receptor and progesterone receptor) status in a series of more than 400 cases of breast cancer analyzed (17). It has been reported that depletion of Prx III in HeLa cells elevates intracellular levels of $\mathrm{H}_{2} \mathrm{O}_{2}$ and sensitizes cells to staurosporine or TNF- $\alpha$ induced apoptosis (18). Similarly overexpressing Prx III-transfected thymoma cells are protected against $\mathrm{H}_{2} \mathrm{O}_{2}$-induced apoptosis (19).

In this study, we examined the immunohistochemical expression of Prx III in breast carcinoma tissues and correlated the expression with PCNA staining, a marker that is used in breast cancer diagnosis and prognosis to evaluate cell proliferation $(20,21)$. We found a positive association of Prx III expression with PCNA immunostaining. To validate the involvement of Prx III in cell proliferation, we determined its expression in breast cancer cell lines and down-regulated Prx III gene and protein expression using small interfering RNA (siRNA). We found that depletion of Prx III inhibited 
cell proliferation and cell cycle progression in MDA-MB-231 breast cancer cells.

\section{Materials and methods}

Clinical specimens. A total of 106 cases of archival invasive ductal breast cancers obtained from patients who had surgery at the Singapore General Hospital (SGH) and approved by the Institutional Review Board were used in this study. The biopsies were fixed in $10 \%$ formalin and tissue microarrays were constructed. The histological diagnosis was made on hematoxylin and eosin (H\&E) stained slides according to standard criteria.

Immunohistochemistry. Immunohistochemistry was carried out on breast tissue microarrays by an automated method with the Leica Bond ${ }^{\mathrm{TM}}$ system. Polyclonal Prx III antibody (1:1500 dilution) and PCNA antibody (1:200 dilution) were used for the immunohistochemical staining. Negative control was performed by using the diluent in place of the primary antibodies. The immunohistochemical staining results of the patients tissues were evaluated based on the percentage of tumor cells stained with Prx III and PCNA antibodies.

Cell culture. Breast cancer cell lines were obtained from America Type Culture Collection (Rockville, MD). MCF-7 breast cancer cells were cultured in Dulbecco's modified Eagle's medium (DMEM) with 10\% fetal bovine serum (FBS) (Hyclone Laboratories, Logan, UT). MDA-MB-231 breast cancer cells were grown in RPMI-1640 containing 10\% FBS. Both cell lines were grown in an incubator at $37^{\circ} \mathrm{C}$ with $5 \%$ $\mathrm{CO}_{2} / 95 \%$ air.

Real-time reverse transcription-polymerase chain reaction (real-time RT-PCR). Total RNA was extracted from cells using the RNeasy ${ }^{\circledR}$ Mini Kit (Qiagen GmbH, Germany). The quantity and quality of total RNA were quantified with the NanoDrop ND-1000 Spectrophotometer (Thermo Scientific Inc., Waltham, MA) via measurement of the absorbance of the RNA sample at a wavelength of 260 and $280 \mathrm{~nm}$. RNA $(1 \mu \mathrm{g})$ was reverse transcribed to cDNA using the SuperScript ${ }^{\mathrm{TM}}$ III First-Strand Synthesis System (Invitrogen, Carlsbad, CA) with random hexamers according to the manufacturer's protocol. The resulting cDNA was diluted and used as a template for real-time PCR using LightCycler (Roche Diagnostics GmbH, Mannheim, Germany). The primer sequences for Prx III used were: 5'-TTA AAC ATG GTT AGT TGC TAG TAC AAG GA-3' forward primer, 5'-TTG AGA CAT GAT CTA AGA ATA GCC TTC TA-3' reverse primer; and for GAPDH 5'GAA GGT GAA GGT CGG AGT CAA-3' forward primer and 5'-TGC CAT GGG TGG AAT CAT ATT GG-3' reverse primer. The PCR conditions used were initial denaturation at $95^{\circ} \mathrm{C}$ for $15 \mathrm{~min}$, followed by 45 cycles of denaturation at $94^{\circ} \mathrm{C}$ for $15 \mathrm{sec}$, annealing at $60^{\circ} \mathrm{C}$ for $25 \mathrm{sec}$ and extension at $72^{\circ} \mathrm{C}$ for $15 \mathrm{sec}$.

Western blotting. Cells were washed with PBS and lysed using ice-cold M-PER ${ }^{\circledR}$ Mammalian Protein Extraction Reagent (Pierce, Rockford, IL) containing EDTA and protease inhibitor. The lysate was collected by centrifugation at $13000 \mathrm{rpm}$ for
$10 \mathrm{~min}$ at $4^{\circ} \mathrm{C}$. The amount of protein was quantified using the Bradford method (Bio-Rad Laboratories, Hercules, CA) and $20 \mu \mathrm{g}$ of protein samples were loaded to $10 \%$ SDS-PAGE gel and were separated by electrophoresis. Separated proteins were then transferred onto a polyvinylidenefluoride (PVDF) membrane (Bio-Rad Laboratories) and blocked overnight in 5\% non-fat milk in Tris-buffered saline with $0.1 \%$ Tween. The blot was incubated with Prx III rabbit polyclonal primary antibody (1:10,000, Abcam, Cambridge, UK) followed by horseradish peroxidase-conjugated donkey anti-rabbit secondary antibody (1:6000, GE Healthcare Ltd, UK). The blot was visualized by Super Signal West Pico Chemiluminescent substrate (Pierce, Rockford, IL, USA). Antibody against Bactin was used as loading control for the experiment. The $\mathrm{X}$ ray film obtained was analysed and quantified by densitometry using the GS-710 densitometer (Bio-Rad) and Quantity One ${ }^{\circledR}$ software.

Immunofluorescence. MCF-7 cells were cultured on Lab$\mathrm{Tek}^{\mathrm{TM}}$ Chambered Coverglass (Thermo Fisher Scientific, Rochester, NY) at a density of $3 \times 10^{4}$ cells per chamber. Upon reaching $70 \%$ confluency, culture media was removed; cells were washed and fixed with $4 \%$ paraformaldehyde (PFA) and permeabilized with $0.1 \%$ Triton X-100 in PBS (PBS-TX). To avoid non-specific binding of antibody, cells were blocked with $1 \%$ bovine serum albumin (BSA) prepared in PBS. Lastly, cells were incubated with Prx III antibodies (1:200 dilution) and FITC conjugated secondary mouse anti-rabbit antibody (1:200, Sigma, St. Louis, MO). Cells were visualized using the Olympus Fluoview ${ }^{\mathrm{TM}}$ confocal microscope (Tokyo, Japan) and confocal fluorescence images were taken.

Transfection with small interfering RNA (siRNA). Human Prx III ON-TARGETplus SMARTpool siRNA and nontargeting pool siRNA were obtained from Dharmacon (Chicago, IL). The siRNAs include Prx III siRNA duplex no. 1 (5'-GUAGAUCACCCAUGUGUAU-3'), duplex no. 2 (5'-GAACAUCGCACUCUUGUCA-3'), duplex no. 3 (5'-AGA CUACGGUGUGCUGUUA-3') and duplex no. 4 (5'-GAGC UUGACAAAUUUAUUG). Cells were seeded onto 6-well plates at a density of $2.5 \times 10^{5}$ cells/well for $24 \mathrm{~h}$ before transfection. MDA-MB-231 breast cancer cells were transfected with siPrx3 and non-targeting pool siRNA was used as a control. The siRNAs were prepared at a final concentration of $20 \mathrm{nmol} / \mathrm{l}$ with DharmaFECT 1 transfection reagent and added to cells for $24 \mathrm{~h}$ according to the manufacturer's instructions. MDA-MB-231 cells were harvested at $48 \mathrm{~h}$ for total RNA preparation and gene expression analysis or at $72 \mathrm{~h}$ for protein extraction.

Cell viability assay. Cell viability was examined with the CellTiter 96 ${ }^{\circledR}$ AQueous Non-Radioactive Cell Proliferation Assay (Promega, Madison, WI). The dye solution was added to the cells at $48 \mathrm{~h}$ post transfection and incubated for up to $4 \mathrm{~h}$ at $37^{\circ} \mathrm{C}$ in a humidified, $5 \% \mathrm{CO}_{2}$ incubator. The absorbance was read at $490 \mathrm{~nm}$ using the Tecan 2000 microplate reader.

Cell cycle analysis. Control and transfected cells were harvested at $48 \mathrm{~h}$ and pelleted by centrifugation. Cell pellet was 


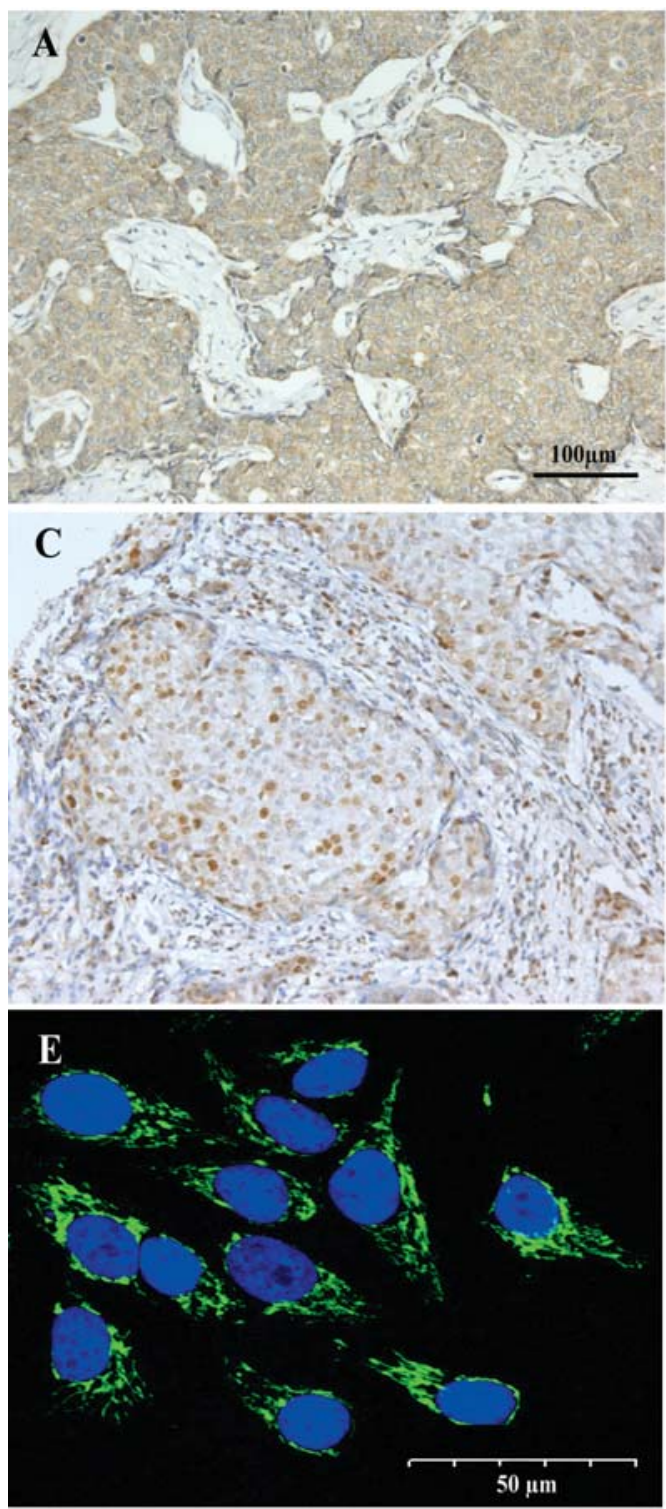

resuspended in $0.5 \mathrm{ml} \mathrm{PBS}$ and fixed in $4.5 \mathrm{ml} 70 \%$ cold ethanol overnight at $4^{\circ} \mathrm{C}$. Ethanol-fixed cells were washed twice with PBS before resuspending with $200 \mu \mathrm{g} / \mathrm{ml}$ propidium iodide solution containing $1 \mathrm{mg} / \mathrm{ml}$ RNAse A, PBS and Triton-X. Cells were incubated at room temperature for $30 \mathrm{~min}$ to allow the DNA content of cells to be stained before analysis by flow cytometry.

Statistical analysis. The GraphPad Prism software (San Diego, CA) was used for statistical analysis. For the TMA immunostaining results, Spearman's correlation was used to compare between continuous variables. Unpaired t-test was performed for comparison of two groups in the in vitro experiments. The in vitro data were expressed as mean \pm SEM of at least three independent experiments. $\mathrm{p}<0.05$ was considered as statistically significant.

\section{Results}

Prx III expression correlates with PCNA immunohistochemical staining. All the 106 breast cancer sections showed positive

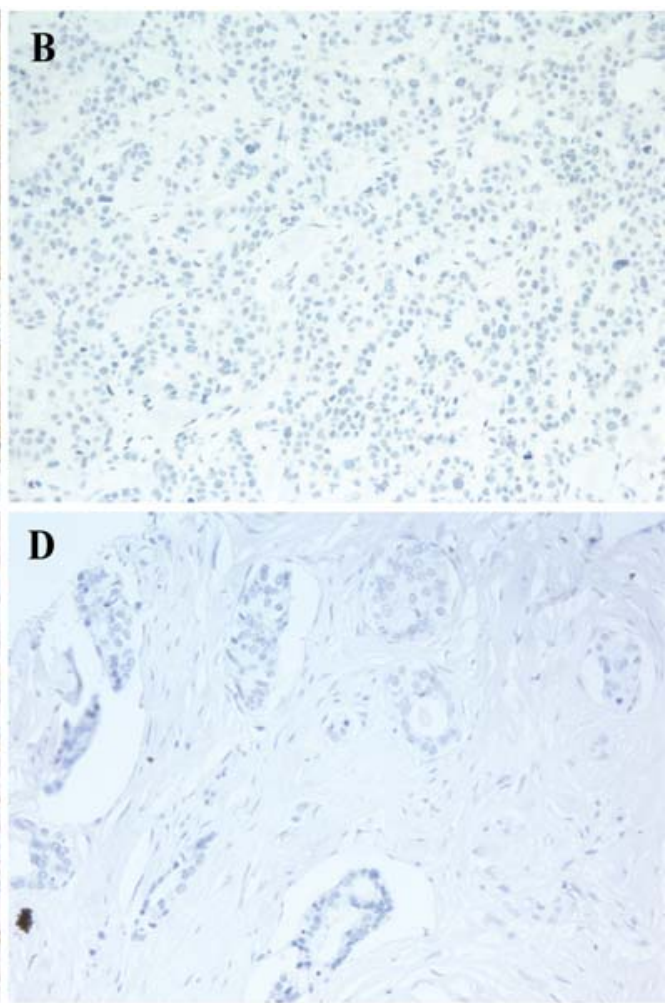

Figure 1. Immunohistochemical expression of Prx III and PCNA in breast cancer. (A) Positive immunostaining of Prx III in patient breast tumour sections. (B) Negative control for Prx III immunostaining in breast cancer tissue section. (C) Positive nuclear PCNA staining in breast cancer tissue. (D) Negative PCNA staining in breast cancer tissue. (E) Prx III immunofluorescence staining in MCF-7 breast cancer cells. Nuclei were counterstained blue with DAPI dye. Confocal microscopy; bar, $50 \mu \mathrm{m}$.

staining for Prx III (Fig. 1A). Prx III immunostaining was localized to the cytoplasm as opposed to the negative control in which there was no staining observed (Fig. 1B). Positive PCNA staining was present in the nuclei of breast cancer cells in 100 out of 106 (94.3\%) breast cancer cases (Fig. 1C). Six out of $106(5.7 \%)$ breast cancer sections had negative PCNA staining (Fig. 1D). In addition, a significant positive relationship was observed between the expression of Prx III and PCNA immunostaining $(\mathrm{p}=0.0295 ; \mathrm{r}=0.2116)$. Breast cancer sections with higher Prx III staining were associated with increased PCNA labeling.

Prx III is expressed in MCF-7 and MDA-MB-231 breast cancer cell lines. To evaluate the expression of Prx III levels in non-invasive MCF-7 breast cancer cells and highly invasive MDA-MB-231 breast cancer cells, real-time RT-PCR and Western blotting were performed. Prx III was found to be expressed in both breast cancer cell lines at mRNA and protein levels (Fig. 2). Immunofluorescence revealed the localization of Prx III as a diffuse speckled pattern in the cytoplasm of MCF-7 cells (Fig. 1E). 
A

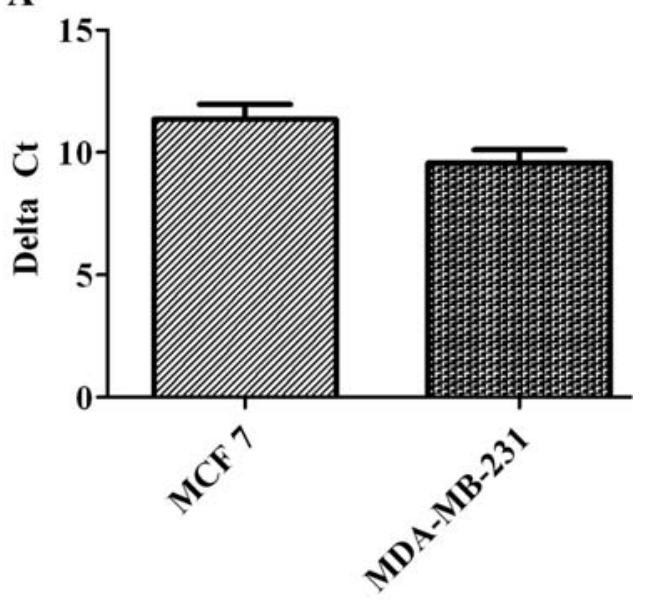

B

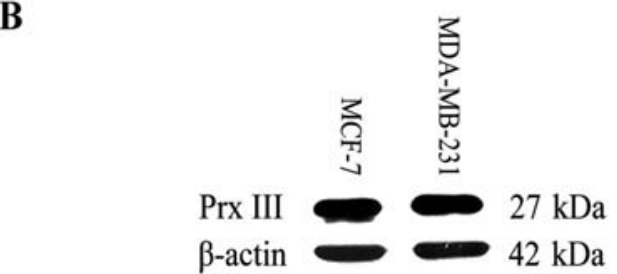

Figure 2. Expression of Prx III mRNA and proteins in MCF-7 and MDAMB-231 cell lines. (A) Expression of Prx III mRNA was detected in both breast cancer cell lines. Bar charts show the $\Delta \mathrm{Ct}$ values for Prx III expression after normalizing to G3PDH gene expression. The higher the $\triangle \mathrm{Ct}$ level, the lower the expression. (B) Western blot analysis showing protein bands of Prx III and B-actin from MCF-7 and MDA-MB-231 breast cancer cells. Bar charts show the optical density (OD) ratio of Prx III protein expression in both cell lines with $\beta$-actin as the loading control. Experiments were done in triplicates. Data are expressed as means \pm SEM. ${ }^{*} \mathrm{p}<0.05$.

Silencing of Prx III gene inhibits cell proliferation. Transfection of MDA-MB-231 cells with siRNA targeted against Prx III successfully reduced Prx III mRNA level by $97 \%$ at $48 \mathrm{~h}$ post transfection (Fig. 3A). Down-regulation of the Prx III protein was verified by Western blot analysis at $72 \mathrm{~h}$ posttransfection which showed a reduction in the expression of Prx III protein by $83.6 \%$ (Fig. 3B). Cell proliferation was significantly inhibited by $49 \%$ in siPrx III treated cells as compared to siNegative treated cells at $48 \mathrm{~h}$ post-transfection (Fig. 4, $\mathrm{p}=0.0027$ ).

Silencing of Prx III gene induces dysregulation of the cell cycle. In addition, silencing of the Prx III gene also increased the percentages of cells in sub-G1 and G1 phases and decreased the percentages of cells in the $\mathrm{S}$ and G2/M phases (Fig. 5).

A

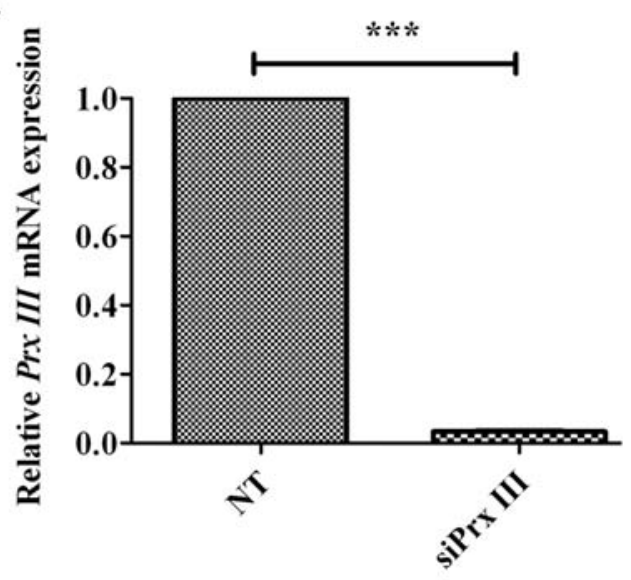

B
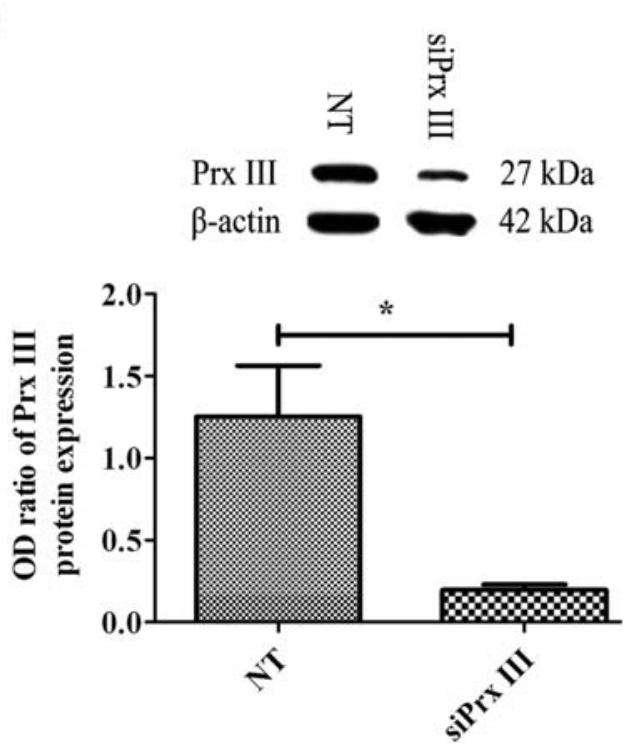

Figure 3. siPrx III down-regulates the expression of Prx III at both mRNA and protein levels. (A) MDA-MB-231 cells were seeded on 6-well plate and transfection with siNegative control and siPrx III were carried out. Total RNA was extracted $48 \mathrm{~h}$ post-transfection and $1 \mu \mathrm{g}$ of RNA for each sample was converted to cDNA. mRNA expression of Prx III was analyzed using qualitative real-time RT-PCR. (B) Protein extraction was done $72 \mathrm{~h}$ posttransfection and Western blotting was performed using antibodies against Prx III and B-actin (loading control for the experiment). A representative blot is shown with densitometric quantification of the protein bands. Experiments were done in triplicates. Data are expressed as means \pm SEM. ${ }^{* * *} \mathrm{p}<0.001$.

There was a slight increase in the percentage of apoptotic cells in siPrx III treated cells as compared to siNegative treated cells from 1.8 to $2.1 \%(\mathrm{p}=0.0309)$. siPrx III treated cells showed a significantly higher percentage of cells in the G1 phase $(62 \%)$ as compared to siNegative treated cells (57\%; $\mathrm{p}=0.0282)$. A decrease in the number of cells in $\mathrm{S}$ phase was also observed for siPrx III treated cells as compared to siNegative treated cells (8.5\% compared with 9.5\%, $\mathrm{p}=0.045)$. For the $\mathrm{G} 2 / \mathrm{M}$ phase, there was a significant reduction in the percentage of cells in siPrx III treated cells $(16.5 \%)$ as compared with siNegative treated cells $(20.7 \%$; $\mathrm{p}=0.0047)$. The sum total of the $\mathrm{S}$ phase and G2/M phase, which is indicative of cell proliferation, was significantly higher in siNegative treated cells $(30.2 \%)$ as compared with siPrx III treated cells $(25 \%)$. 


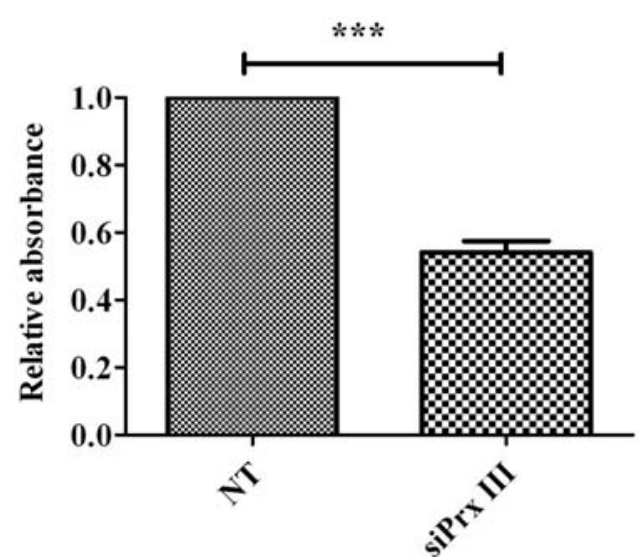

Figure 4. Silencing of $\operatorname{Prx} I I I$ gene induces anti-proliferative activity by inhibiting cell proliferation in MDA-MB-231 breast cancer cells. Cell proliferation at $48 \mathrm{~h}$ post-transfection was determined by CellTiter $96^{8}$ AQueous Non-Radioactive Cell Proliferation Assay. The absorbance was measured at $490 \mathrm{~nm}$ wavelength by using a microplate reader. Data shown are means \pm SEM of three independent experiments. ${ }^{* * *} \mathrm{p}<0.001$.

A

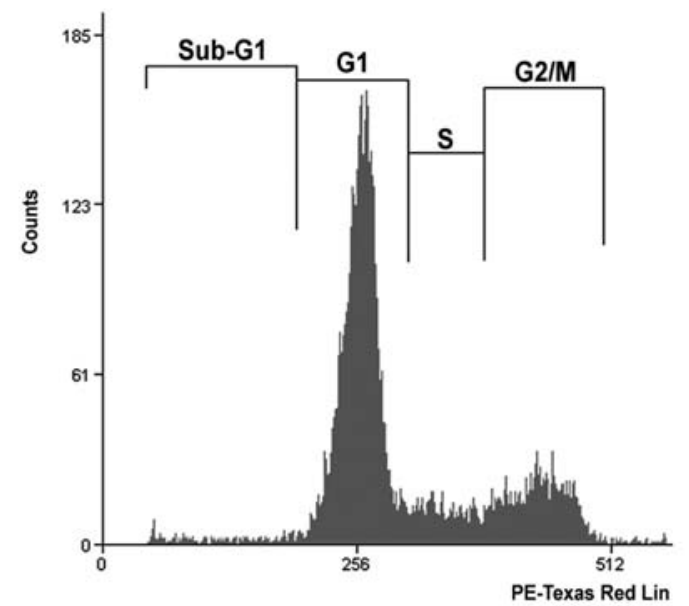

B

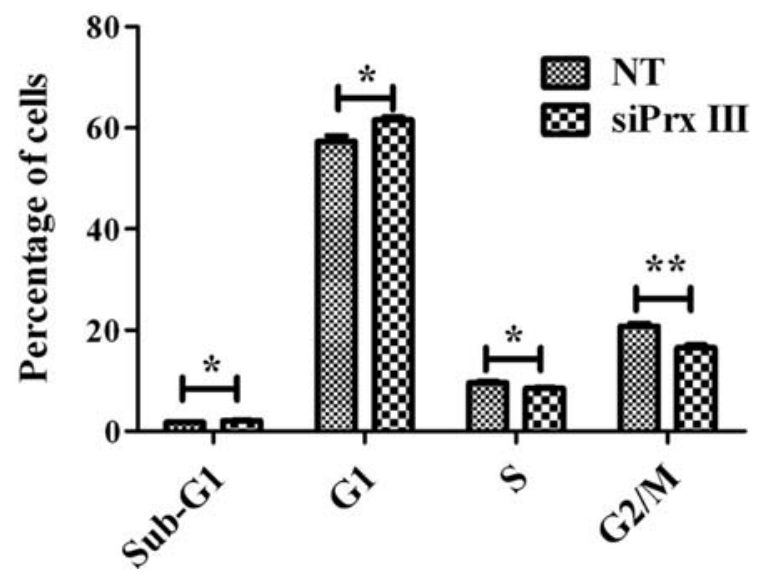

Figure 5. Silencing of Prx III gene affects the cell cycle phases in MDAMB-231 breast cancer cells. (A) Representative cell cycle profile for siPrx III treated cells. The DNA content of cells were stained with propidium iodide and analyzed with flow cytometry. (B) The bar chart shows the percentage of cells in various phases of cell cycle for siNegative treated cells and siPrx III treated cells at $48 \mathrm{~h}$ post-transfection. ${ }^{*} \mathrm{p}<0.05$ and ${ }^{* * *} \mathrm{p}<0.01$.

\section{Discussion}

The multifunctional Prx family of proteins has been implicated in breast carcinogenesis. Prx I has been shown to suppress oncogenic Ras effector pathways in mammary epithelial cells by regulating PTEN/AKT activity (22). Prx II has been reported to induce resistance of breast cancer cells to ionizing radiation by reducing intracellular reactive oxygen species levels (23). Prxs IV and VI are reported to be overexpressed in progesterone receptor-positive breast cancer cases and Prx V expression has been associated with larger tumor size and positive lymph node status (17). Overexpression of Prx III in breast cancer tissues as compared to normal breast epithelial cells which have been previously reported $(16,17)$ could confer selective advantage to carcinomas. Our data showed a positive correlation between cell proliferation (a hallmark of cancer) determined by PCNA immunohistochemical staining and Prx III expression in breast cancer tissues.

To validate the immunohistochemical findings in the TMAs, we successfully knocked down Prx III mRNA and protein expression in MDA-MB-231 breast cancer cells using short interfering RNA. We observed a decrease in cell proliferation and cell cycle progression, affecting mainly the $\mathrm{S}$ phase and $\mathrm{G} 2 / \mathrm{M}$ phase which are the proliferative phases of the cell cycle. Mitochondrial Prx III has been reported to be an important regulator of $\mathrm{H}_{2} \mathrm{O}_{2}$ in the cell (19). We have also recently shown that high levels of hydrogen peroxide induced G1/S phase cell cycle arrest with increased apoptosis in MCF-7 breast cancer cells with modulation of Cytoglobin, Forkhead box M1, NADPH oxidase (Nudix nucleoside diphosphate linked moiety $X)$-type motif 1 and Selenoprotein $P 1$ genes (24).

On the other hand, low levels of $\mathrm{H}_{2} \mathrm{O}_{2}$ may be involved in oxidative stress mediated signaling, serving as a secondary messenger which activate multiple signal transduction pathways (25). Low or intermediate levels of oxidative stress have been reported to be pro-tumorigenic, promoting proliferation of cells, tumor development and progression $(26,27)$. Besides controlling the concentration of $\mathrm{H}_{2} \mathrm{O}_{2}$, Prx III, a 2-Cys Prx has the distinctive feature of undergoing reversible substratemediated inactivation and hence, provides a redox-switch mechanism which could regulate oxidative stress mediated signaling relative to the levels of $\mathrm{H}_{2} \mathrm{O}_{2}$ (28). It has been reported that $\mathrm{H}_{2} \mathrm{O}_{2}$ activates apoptosis signal-regulating kinase 1 , a serine-threonine kinase which subsequently stimulates both the p38 and c-Jun N-terminal kinase (JNK) pathways, and induces a variety of cellular responses such as proliferation and apoptosis (29).

Markers of proliferation which have been investigated in breast cancer include proliferation associated antigens such as Ki-67 and MIB 1, cyclins such as cyclin E and cyclin D1, cyclin-dependent kinase inhibitors such as p27, p21 wAF1 (wild-type p53 activated fragment 1) also known as cyclindependent kinase-interacting protein 1 (CIP1) and topoisomerase II $\alpha$, an essential nuclear DNA-binding enzyme (30). In the more recent studies, Cyclin A was found to be a proliferative marker with good prognostic value in axillary lymph node-negative breast cancer patients (31) and transferrin receptor, CD71, which is involved in the cellular uptake of iron, was observed to promote growth of endocrine 
resistant breast cancer phenotypes (32). Metallothionein, the metal binding family of proteins are reported to increase cell proliferation in breast cancer (33) and specifically the MT-2A isoform via the ATM/Chk2/ cdc25A pathway (34). Proteolytic conversion of syndecan-1 (a heparan sulfate proteoglycan) from a membrane-bound into a soluble molecule was observed to transform MCF 7 breast cancer cells from a proliferative to an invasive phenotype (35).

In conclusion, we have shown in this study that Prx III expression is correlated with cell proliferation in breast cancer tissues. The in vitro experiments have verified that Prx III is important for cell proliferation in breast cancer cells. Further studies to elucidate the detailed mechanistic pathway(s) by which Prx III affects cell proliferation would provide valuable information on the factors influencing progression of breast cancer, allowing the development of therapeutic strategies. Taken together, Prx III could be a potential molecular therapeutic target and a useful proliferation marker in breast cancer.

\section{Acknowledgements}

The authors are grateful to Ms. Song Lin Bay for technical assistance. The research work was supported by Grants NMRC/1081/2006 and NMRC/1019/2005 from the National Medical Research Council, Singapore.

\section{References}

1. Stewart BW and Kleihues P: World Cancer Report. IARC Press, Lyon, 2003.

2. Stingl J and Caldas C: Molecular heterogeneity of breast carcinomas and the cancer stem cell hypothesis. Nat Rev Cancer 7: 791-799, 2007.

3. Vargo-Gogola T and Rosen JM: Modelling breast cancer: one size does not fit all. Nat Rev Cancer 7: 659-672, 2007.

4. Kim HK, Kim SJ, Lee JW, Lee JW, Cha MK and Kim IH: Identification of promoter in the 5'-flanking region of the E. coli thioredoxin-linked thiol peroxidase gene: evidence for the existence of oxygen-related transcriptional regulatory protein. Biochem Biophys Res Commun 221: 641-646, 1996.

5. Chae HZ, Robison K, Poole LB, Church G, Storz G and Rhee SG: Cloning and sequencing of thiol-specific antioxidant from mammalian brain: alkyl hydroperoxide reductase and thiolspecific antioxidant define a large family of antioxidant enzymes. Proc Natl Acad Sci USA 91: 7017-7021, 1994.

6. Hofmann B, Hecht HJ and Flohe L: Peroxiredoxins. Biol Chem 383: 347-364, 2002.

7. Rhee SG, Kang SW, Chang TS, Jeong W and Kim K: Peroxiredoxin, a novel family of peroxidases. IUBMB Life 52 $35-41,2001$.

8. Wood ZA, Schroder E, Robin HJ and Poole LB: Structure, mechanism and regulation of peroxiredoxins. Trends Biochem Sci 28: 32-40, 2003.

9. Verdoucq L, Vignols F, Jacquot JP, Chartier Y and Meyer Y: In vivo characterization of a thioredoxin $\mathrm{h}$ target protein defines a new peroxiredoxin family. J Biol Chem 274: 19714-19722, 1999.

10. Fujii $\mathrm{J}$ and Ikeda $\mathrm{Y}$ : Advances in our understanding of peroxiredoxin, a multifunctional, mammalian redox protein. Redox Rep 7: 123-130, 2002.

11. Rhee SG, Chae HZ and Kim K: Peroxiredoxins: a historical overview and speculative preview of novel mechanisms and emerging concepts in cell signaling. Free Radic Biol Med 38: 1543-1552, 2005.

12. Araki M, Nanri H, Ejima K, Murasato Y, Fujiwara T, Nakashima $\mathrm{Y}$ and Ikeda $\mathrm{M}$ : Antioxidant function of the mitochondrial protein SP-22 in the cardiovascular system. J Biol Chem 274: 2271-2278, 1999.

13. Watabe S, Hiroi T, Yamamoto Y, Fujioka Y, Hasegawa H, Yago N and Takahashi SY: SP-22 is a thioredoxin-dependent peroxide reductase in mitochondria. Eur J Biochem 249: 52-60, 1999.
14. Wonsey DR, Zeller KI and Dang CV: The c-Myc target gene PRDX3 is required mitochondrial homeostasis and neoplastic transformation. Proc Natl Acad Sci USA 99: 6649-6654, 2002.

15. Choi JH, Kim TN, Kim S, Baek SH, Kim JH, Lee SR and Kim JR: Overexpression of mitochondrial thioredoxin reductase and peroxiredoxin III in hepatocellular carcinomas. Anticancer Res 22: 3331-3335, 2002.

16. Noh DY, Ahn SJ, Lee RA, Kim SW, Park IA and Chae HZ: Overexpression of peroxiredoxin in human breast cancer. Anticancer Res 21: 2085-2090, 2001.

17. Karihtala P, Mantyniemi A, Kang SW, Kinnula VL and Soini Y: Peroxiredoxins in breast carcinoma. Clin Cancer Res 9: 3418-3424, 2003.

18. Chang TS, Cho CS, Park S, Yu S, Kang SW and Rhee SG: Peroxiredoxin III, a mitochondrion-specific peroxidase, regulates apoptotic signaling by mitochondria. J Biol Chem 279: 41975-41984, 2004.

19. Nonn L, Berggren M and Powis G: Increased expression-of mitochondrial peroxiredoxin-3 (thioredoxin peroxidase-2) protects cancer cells against hypoxia and drug-induced hydrogen peroxide-dependent apoptosis. Mol Cancer Res 1: 682-689, 2003.

20. Aaltomaa S, Lipponen P and Syrjanen K: Proliferating cell nuclear antigen (PCNA) immunolabeling as a prognostic factor in axillary lymph node negative breast cancer. Anticancer Res 13: 533-538, 1993.

21. Tsurimoto T: PCNA, a multifunctional ring on DNA. Biochim Biophys Acta 1443: 23-39, 1998.

22. Cao J, Schulte J, Knight A, Leslie NR, Zagozdzon A, Bronson R, Manevich Y, Beeson C and Neumann CA: Prdx 1 inhibits tumorigenesis via regulating PTEN/AKT activity. EMBO J 28: 1505-1517, 2009.

23. Wang T, Tamae D, LeBon T, Shively JE, Yen Y and Li JJ: The role of peroxiredoxin II in radiation-resistant MCF-7 breast cancer cells. Cancer Res 65: 10338-10346, 2005.

24. Chua PJ, Yip GW and Bay BH: Cell cycle arrest induced by hydrogen peroxide is associated with modulation of oxidative stress related genes in breast cancer cells. Exp Biol Med (Maywood) 234: 1086-1094, 2009.

25. Droge W: Free radicals in the physiological control of cell function. Physiol Rev 82: 47-95, 2002.

26. Visconti R and Grieco D: New insights on oxidative stress in cancer. Curr Opin Drug Discov Dev 12: 240-245, 2009.

27. Fang J, Seki $\mathrm{T}$ and Maeda $\mathrm{H}$ : Therapeutic strategies by modulating oxygen stress in cancer and inflammation. Adv Drug Deliv Rev 61: 290-302, 2009.

28. Fourquet S, Huang ME, D'Autreaux B and Toledano MB: The dual functions of thiol-based peroxidases in $\mathrm{H}_{2} \mathrm{O}_{2}$ scavenging and signaling. Antioxid Redox Signal 10: 1565-1576, 2009.

29. Matsukawa J, Matsuzawa A, Takeda K and Ichijo H: The ASK1-MAP kinase cascades in mammalian stress response. J Biochem 136: 261-265, 2004.

30. Colozza M, Azambuja E, Cardoso F, Sotiriou C, Larsimont D and Piccart MJ: Proliferative markers as prognostic and predictive tools in early breast cancer: where are we now? Ann Oncol 16: 1723-1739, 2005.

31. Ahlin C, Zhou W, Holmqvist M, Holmberg L, Nilsson C, Jirström K, Blomqvist C, Amini RM and Fjällskog ML: Cyclin A is a proliferative marker with good prognostic value in node-negative breast cancer. Cancer Epidemiol Biomarkers Prev 18: 2501-2506, 2009.

32. Habashy HO, Powe DG, Staka CM, Rakha EA, Ball G, Green AR, Aleskandarany M, Paish EC, Douglas Macmillan R, Nicholson RI, Ellis IO and Gee JM: Transferrin receptor (CD71) is a marker of poor prognosis in breast cancer and can predict response to tamoxifen. Breast Cancer Res Treat (In press)

33. Pedersen MØ, Larsen A, Stoltenberg M and Penkowa M: The role of metallothionein in oncogenesis and cancer prognosis. Prog Histochem Cytochem 44: 29-64, 2009.

34. Lim D, Jocelyn KM, Yip GW and Bay BH: Silencing the Metallothionein-2A gene inhibits cell cycle progression from G1- to S-phase involving ATM and cdc25A signaling in breast cancer cells. Cancer Lett 276: 109-117, 2009.

35. Nikolova V, Koo CY, Ibrahim SA, Wang Z, Spillmann D, Dreier R, Kelsch R, Fischgräbe J, Smollich M, Rossi LH, Sibrowski W, Wülfing P, Kiesel L, Yip GW and Götte M: Differential roles for membrane-bound and soluble syndecan-1 (CD138) in breast cancer progression. Carcinogenesis 30: 397-407, 2009. 